\title{
INFORMACIONO-KOMUNIKACIONE TEHNOLOGIJE U SLUŽBI KULTURNOG TURIZMA
}

\section{Dragana Ćamilović}

Visoka hotelijerska škola, Beograd, Srbija
Correspondence:

Dragana Ćamilović

e-mail:

dragana.camilovic@vhs.edu.rs

\section{Rezime:}

Tržište kulturnog turizma postaje sve značajniji segment turističkog tržišta, jer broj kulturnih turista raste iz godine u godinu. Međutim, sve veća je i konkurencija među različitim kulturnim turističkim destinacijama. U digitalnom dobu u kome živimo, turisti za pretraživanje informacija pri planiranju putovanja koriste u velikoj meri internet. Zbog toga posebnu pažnju treba posvetiti, kako prisustvu na internetu, tako i na društvenim mrežama. Na koji način kulturni turisti koriste informaciono-komunikacione tehnologije (IKT), ali i kakav sajt treba da imaju turističke organizacije i ustanove kulture, neke su od tema obrađenih u ovom radu. Osim toga, istražene su i mogućnosti upotrebe mobilnih aplikacija u kulturnom turizmu, posebno mobilnih turističkih vodiča i mobilnih aplikacija muzeja i galerija. Korak dalje je upotreba proširene tj. izmenjene, kao i virtuelne stvarnosti, što je takođe prikazano u ovom radu. Primena savremenih tehnologija omogućava kreiranje dodatne vrednosti za turiste i svakako doprinosi njihovom većem zadovoljstvu, pa je verovatno da će svoja pozitivna iskustva podeliti na društvenim mrežama i dati dobru ocenu na nekom od sajtova, kao što je TripAdvisor. Moguće je, međutim, i koristiti influenserski marketing u cilju promovisanja destinacije kulturnog turizma.

Ključne reči:

kulturni turizam, društvene mreže, mobilne aplikacije, proširena stvarnost, virtuelna stvarnost

UVOD

U globalističkoj eri u kojoj danas živimo, uticaj informaciono-komunikacionih tehnologija (IKT) na razvoj kulturnog turizma je veliki, pre svega iz razloga što turisti pri planiranju svojih putovanja koriste internet i sve raspoložive informacije na njemu. Dalje, u toku samog putovanja neretko koriste aplikacije koje besplatno mogu instalirati na svoj mobilni telefon. Ustanove kulture, poput muzeja i galerija, mogu koristiti IKT u cilju unapređenja iskustava posetilaca, npr. multimedijalne vodiče kroz izložbe, proširenu ili čak virtuelnu stvarnost. $O$ svemu ovome će biti reči u nastavku rada, ali pre toga treba razmotriti šta podrazumevamo pod pojmom kulturni turizam i kakav je profil kulturnih turista. 
U literaturi se najčešće pominje definicija kulturnog turizma koju je dala Svetska turistička organizacija (UNWTO) 1985. godine. Tako se kulturni turizam posmatra kao kretanje ljudi sa suštinski kulturnom motivacijom, kao što su studijska putovanja, putovanja radi posete umetničkim događajima, kulturne ture, putovanja na festivale i druge kulturne događaje, posete istorijskih mesta i spomenika, putovanja u cilju proučavanja prirode, folklora ili umetnosti i hodočašće (Talwar, 2006, p. 8). Kulturni turizam se ranije smatrao malom turističkom nišom, dok danas doživljava svoju ekspanziju. UNWTO predviđa porast potražnje u sektoru kulturnog turizma za 15\% u godinama koje su pred nama (Goss, 2016). Strategija razvoja turizma Republike Srbije za period od 2016. do 2025. godine prepoznaje porast poseta najznačajnijim segmentima pokretnog, nepokretnog, i nematerijalnog kulturnog nasleđa (Vlada Republike Srbije, 2016).

Ko su kulturni turisti? Pivac (2016) navodi da su to turisti koji su posetili atrakcije vezane za kulturu i istoriju nekog mesta i naroda, ili su učestvovali u događajima vezanim za lokalnu kulturu. Turisti koji se klasifikuju kao "kulturni turisti", po istraživanjima koje navode Silberberg (1995) i ATLAS-ov izveštaj iz 2007. godine (ATLAS Cultural Tourism Survey 2007), su visoko obrazovani, zaposleni su na višim pozicijama (pa samim tim imaju prihode veće od prosečnog turiste), potroše više novca na putovanje, više kupuju, uglavnom odsedaju u hotelima. Dok je Silberberg (1995) u istraživanju došao do podatka da su kulturni turisti uglavnom pripadnici starije starosne grupe, danas je segment mladih od velikog interesa za kulturni turizam. Niže cene letova (odnosno sve veći broj destinacija pokriven letovima low cost kompanija) i raspoloživost jeftinog smeštaja (hosteli i sl.), utiču na to da mladi ljudi sve češće putuju. Segment mladih je značajan za kulturni turizam i iz razloga što iskustva koja turisti stiču u mladosti mogu u velikoj meri uticati na njihova turistička ponašanja kasnije u životu.

Prema Hadžiću (2005) postoji nekoliko vrsta kulturnog turizma: religiozni (obrazovni religiozni turizam, hodočašće, misionarstvo), obrazovni (obrazovna putovanja, kongresni), festivalski (folklorni praznici, festivali različitih vrsta umetnosti), kulturni turizam povezan sa kulturno-istorijskim nasleđem (istorijski i arhitektonski spomenici, muzeji i galerije), kao i nematerijalni kulturni turizam (upoznavanje sa životom lokalnog stanovništva i sl.). U ovom radu akcenat je stavljen na proučavanje upotrebe IKT u cilju unapređenja turizma povezanog sa kulturno-istorijskim i arhitektonskim spomenicima. Pri tome će posebno biti razmatrana uloga IKT u fazi planiranja putovanja, $\mathrm{u}$ toku samog putovanja, kao i u fazi nakon realizovanog putovanja.

\section{INFORMACIONO-KOMUNIKACIONE TEHNOLOGIJE PRI PLANIRANJU PUTOVANJA}

Turisti u fazi planiranja putovanja u velikoj meri istražuju podatke i informacije koje su im dostupne na internetu. Pri tome ogromna većina njih za tu svrhu koristi pretraživače veba (Qian et al., 2015), kao što su Google, Yahoo, Bing itd. Prilikom istraživanja određene destinacije, turisti pretražuju i informacije o njenom kulturno-istorijskom nasleđu. Iz ovog razloga je vrlo bitno da turističke organizacije, ali i različite ustanove kulture (npr. galerije, muzeji) budu ne samo prisutne na internetu, već i da njihovi veb sajtovi budu dobro pozicionirani u rezultatima pretrage. Posebnu pažnju treba posvetiti optimizaciji sajta za pretraživače (Search Engine Optimisation - SEO). SEO, dakle, treba da posredstvom različitih pretraživača dovede nove potencijalne turiste na sajt turističke organizacije ili ustanove kulture.

Sajt treba i da bude funkcionalan, jednostavan i da zadovoljava estetske kriterijume (Lončarić et al., 2015). Sledeća stavka koja je jako bitna jeste da sajt bude prilagođen i za mobilne uređaje (mobile-friendly), jer turisti za pretraživanje informacija neretko koriste mobilne telefone i tablete. Naravno, treba da postoji verzija sajta na engleskom jeziku, a poželjno i na više stranih jezika. Tako je na sajtu Turističke organizacije Srbije (koji se nalazi na adresi http://www.srbija.travel/) pored srpskog i engleskog, moguće odabrati i neki od sledećih jezika: francuski, ruski, italijanski, španski, nemački, japanski i kineski.

Bitna je i povezanost sajta sa profilima na društvenim mrežama. Vrlo često se dešava da kao rezultat pretraživanja na nekom pretraživaču veba bude ponuđena npr. stranica na Facebook-u. Imajući u vidu da je putovanje u svojoj osnovi iskustveno, društvene mreže predstavljaju važan izvor informacija u fazi planiranja putovanja (Schroeder and Pennington-Gray, 2015). Praksa pokazuje da društvene mreže imaju veliku 
uticaj na kreiranje želje da se neka destinacija poseti. Svaka objava (post), bilo da je tekstualna, ili da je reč o slici ili video snimku, može inspirativno delovati na turistu i inicirati sakupljanje dodatnih informacija o toj destinaciji (Minazzi, 2015). Važi i obrnuto: turisti često na društvenim mrežama proveravaju informacije do kojih su došli iz drugih izvora na internetu, a neretko koriste ovaj kanal komunikacije da postavljaju dodatna pitanja. Naravno, pri tome očekuju da im se blagovremeno na njih odgovori. Zato je za ustanove kulture značajno da koriste nove tehnologije kao što su chat botovi. Facebook je ih je uveo još 2016. godine (Florian et al., 2017). Messenger chat botovi su aplikacije koje se povezuju sa Facebook stranicom i omogućavaju upravljanje porukama na stranici (Mondo, 2017). Inače, chat botovi su aplikacije koje omogućavaju interakciju između ljudi i računara na prirodnom jeziku, pri čemu nekima treba izdati naredbe, kako bi izvršili određeni zadatak, dok su drugi dizajnirani tako da mogu da nastave razgovor (Baechle, 2018). Na ovaj način je komunikacija automatizovana, pa se na pitanja turista može odgovarati u bilo koje doba dana i noći, bez stvarne potrebe dežuranja ljudi. Prema podacima Facebook-a, aktivnost chat botova se u periodu od januara 2017. do januara 2018. uvećala čak 5,6 puta (Hundertmark, 2018). Naravno, korišćenje chat botova nije ograničeno samo na $F a-$ cebook, oni se mogu koristiti u različitim oblicima online komunikacije, npr. na samom veb sajtu, aplikacijama kao što je WhatsApp i slično. Posebnu kategoriju čine chat botovi koji imaju razvijenu komponentu veštačke inteligencije (artificial intelligence - AI), zahvaljujući kojoj mogu rešavati i komplikovanije zadatke, a pojedini, zahvaljujući mašinskom učenju (machine learning - ML) mogu i da uče (Joksić, 2018). Pravac u kojem se ova tehnologija danas razvija jeste kreiranje tzv. personalizovanih chat botova, koji će posedovati znanja o ličnim preferencijama, potrebama i navikama korisnika, te personalizovati komunikaciju (Florian et al., 2017).

Iz svega gore navedenog, nameće se zaključak da je prisustvo turističkih organizacija i ustanova kulture na društvenim mrežama jako bitno, kao i način na koji koriste društvene mreže u svrhu promocije i komunikacije sa turistima. Na sajtu Turističke organizacije Srbije postoje veze ka profilima na nekoliko društvenih mreža: Facebook, Twitter, Youtube, Instagram, Pinterest i TripAdvisor. Takođe, treba imati u vidu da se Facebook može koristiti i za oglašavanje, a zbog ogromnog broja korisnika ove društvene mreže, ovo je idealan način da se dođe do potencijalnih posetilaca. Facebook reklame se pojavljuju između objava Facebook prijatelja i imaju oznaku Sponsored. Bitno je da sadržaj reklame bude zanimljiv i primamljiv korisnicima da na njega kliknu.

\section{INFORMACIONO-KOMUNIKACIONE TEHNOLOGIJE U TOKU PUTOVANJA}

Ako na put i ne ponesu prenosni računar, turisti svakako svuda ponesu svoj pametni mobilni telefon. To znači da i u toku samog putovanja intenzivno koriste IKT, i to na različite načine:

- nastavljaju da koriste internet u svrhu dolaska do dodatnih informacija (pogotovo sada kada im je na aerodromima, u hotelima, restoranima i mnogim drugim mestima omogućen besplatan WiFi),

- svoje utiske, slike i snimke sa putovanja objavljuju na društvenim mrežama,

- koriste mobilne aplikacije koje im pomažu u obilasku, tj. mobilne turističke vodiče,

- koriste aplikacije u muzejima i galerijama.

Dodatno pretraživanje informacija na internetu može uticati na odluku turiste o tome koje lokalitete želi da obiđe, jer mnogi ne planiraju putovanja nužno pre polaska, a ako su ga i isplanirali, mogu izmeniti ili proširiti listu kulturno-istorijskih spomenika i ustanova kulture koje žele da posete. Još jedna od aktivnosti turista tokom putovanja jeste postavljanje utisaka na društvenim mrežama i ocena putovanja na različitim sajtovima. Ovo može biti prilika za promociju kulturno-istorijskih znamenitosti, ali isto tako i opasnost da, u slučaju da turista nije bio zadovoljan, negativne recenzije postanu dostupne velikom broju ljudi (Knežević et al., 2017).

Gotovo sve destinacije koje žele da razvijaju kulturni turizam imaju razvijenu bar jednu aplikaciju mobilnog turističkog vodiča. Mobilni turistički vodiči su aplikacije koje korisnicima omogućavaju da se na jednostavan i brz način upoznaju sa informacijama o lokalitetima koje vredi posetiti u mestu boravka. Čine značajnu oblast primene IKT u kulturnom turizmu, jer kulturno nasleđe turistima čine dostupnim i lakše razumljivim (Hausmann et al., 2015). Na ovaj način turisti mogu, i bez vodiča, isplanirati svoje razgledanje, obići sve značajne kulturno-istorijske znamenitosti i saznati pregršt dodatnih informacija o njima. Neke od poželjnih karakteristika ovih aplikacija su sledeće: 
- Besplatne su (mogu se preuzeti na Google Play Store ili App Store),

- Tekstualni sadržaji su dostupni na više jezika,

- Pored tekstualnih, zastupljeni su i audio sadržaji (da bi turista mogao da uživa u razgledanju, umesto da gleda u telefon),

- Postoje verzije za najzastupljenije operativne sisteme (kao što su Android i iOS),

- Da bi se izbegli troškovi rominga, svi sadržaji treba da budu integrisani u aplikaciju,

- Treba da budu jednostavne za korišćenje (user friendly),

- Poželjno je da omogućavaju visok stepen personalizacije (u skladu sa interesovanjima turiste),

- Mogu koristiti savremene koncepte kao što je proširena tj. izmenjena stvarnost.

Proširena ili izmenjena stvarnost (augmented reality - AR) korisniku omogućava da njegov pogled na svet bude proširen informacijama koje se kompjuterski generišu i nadograđuju, uključujući ovde digitalne slike, video zapise, tekstove, zvukove, podatke o GPS lokaciji i slično (Kečkeš and Tomičić, 2017). Tako se turistima na zabavan način predstavljaju dodatne informacije o kulturno-istorijskom nasleđu mesta u kome borave. Aplikacija može koristiti kameru mobilnog telefona i sliku koju korisnik njome vidi dopuniti putokazima do najbližih kulturnih i istorijskih objekata. Takođe, izgled objekata na korisnikovom telefonu može biti proširen njihovim istorijatom i nizom drugih dodatnih informacija, koje mogu biti predstavljene na različite načine (ne nužno tekstualno). Moguća je i 3D rekonstrukcija spomenika, a postoji i mogućnost da se turistima "približe” arheološka nalazišta koja su smeštena na nepristupačnim lokacijama (Fritz et al., 2005). Ove aplikacije bi takođe mogle da turistu "prošetaju" kroz vekove, pa bi tako on mogao da "prisustvuje" bitkama i drugim istorijskim događajima koji su se odigrali na mestu koje obilazi. Mogućnosti su velike, ali je razvoj AR aplikacija i dalje prilično skup poduhvat.

Muzeji i galerije sa tradicionalnih audio vodiča sve više prelaze na mobilne aplikacije. Ove aplikacije omogućavaju vođenje kroz izložbe/postavke, pomažući posetiocima da dobiju mnogo bolje smernice za obilazak, u zavisnosti od njihovih interesovanja, ali i mnogo više informacija o eksponatima. Mogu biti dostupne na više jezika, što je takođe značajno za privlačenje stranih turista. Neke aplikacije daju korisniku mogućnost da omiljena dela podeli na društvenim mrežama, što je veoma značajno za promociju kulturnog nasleđa i same ustanove kulture. Naravno, i ovde postoji mogućnost primene AR-a. Korak dalje je korišćenje virtuelne stvarnosti (virtual reality - VR) u kojoj se stvaran svet zamenjuje virtuelnim. VR je, zapravo, skup tehnologija koje omogućavaju generisanje vizuelnih, zvučnih i ostalih čulnih iskustava. Muzeji i galerije mogu koristiti VR u različite svrhe. Prilikom ponovnog otvaranja, nakon dugogodišnje rekonstrukcije, Narodni muzej u Beogradu je svojim posetiocima pomoću VR-a predstavio i dela koja se nisu našla na izložbi. Zahvaljujući kompaniji Digital Mind, dela Nadežde Petrović, Paje Jovanovića i Vlaha Bukovca postala su dostupna na VR All Art platformi (SEEcult.org, 2018). Britanski muzej je npr. iskoristio VR da svoje posetioce provede kroz bronzano doba, pa su oni mogli da u virtuelnoj stvarnosti vide neke od izloženih eksponata u prvobitnom okruženju (Rae and Edwards, 2016). Proširena i virtuelna stvarnost su sadašnjost i budućnost korišćenja IKT za potrebe razvoja kulturnog turizma.

\section{INFORMACIONO-KOMUNIKACIONE TEHNOLOGIJE NAKON PUTOVANJA}

Iako veliki broj turista objavljuje svoje utiske, slike i video snimke i u toku samog putovanja, deljenje ovakvih sadržaja na društvenim mrežama je u velikoj meri zastupljeno i nakon povratka kući. Prema jednom istraživanju čak 45\% turista nakon putovanja objavi sadržaje o njemu na društvenim mrežama, ili piše online recenzije (Minazzi, 2015; Knežević et al., 2017). Kulturni turisti često vrše ocenjivanja ili daju recenzije i na različitim sajtovima, poput TripAdvisor-a. Tu su i blogovi, na kojima se takođe postavljaju sadržaji o završenom putovanju, uključujući ovde i impresije o kulturno-istorijskim znamenitostima koje su posećene.

Zadovoljni turisti i dobre ocene i recenzije su odlična, i to besplatna, reklama. Pokazalo se da su turisti dodatno stimulisani da ostave pozitivne komentare ukoliko su dobili pismo zahvalnosti nekoliko dana posle posete (Knežević et al., 2017). Tako da ovo može biti jedno od oružja marketinga u kulturnom turizmu. A treba razmišljati i o influenserskom marketingu. Influenseri su osobe koje su uticajne u svom okruženju, koje drugi 
ljudi prate, slušaju i čije savete prihvataju na blogovima i društvenim mrežama. Oni mogu uspešno „dovesti“ kulturne turiste, jer će njihove utiske o poseti nekoj kulturno-istorijskoj znamenitosti pročitati, i verovatno slediti, ogroman broj ljudi. Prema nekim istraživanjima, kompanije zarađuju oko 6,5 dolara za svaki uloženi dolar u influenserski marketing. Konsultantska firma Axon Marketing \& Communications (2018) je u svom istraživanju otkrila da čak $80 \%$ turista smatra da influenseri imaju uticaja na njihov odabir turističke destinacije. Dakle, postoje načini da se utiče na izbor kulturne turističke destinacije, pa turističke organizacije i različite ustanove kulture svakako treba da ih iskoriste.

\section{ZAKLJUČAK}

Broj korisnika interneta u svetu je premašio 4 milijarde, pa je sada više od 50\% populacije online (Kemp, 2018). Tako da veliki broj turista upravo koristi internet za pretraživanje informacija o potencijalnim destinacijama kulturnog turizma. Zbog toga je vrlo važno da im turističke organizacije, kao i ustanove kulture, te informacije obezbede i čak idu i korak dalje kako bi motivisali turiste da od mnoštva destinacija izaberu baš tu.

Kako se, prema istom ovom istraživanju, broj korisnika društvenih mreža sada u svetu popeo na preko 3 milijarde (Kemp, 2018), očigledno je da je bitno i na njima vršiti promociju. Ali pored toga što lepe fotografije, video snimci i sl. mogu kod turiste stvoriti želju da poseti neku kulturnu destinaciju, veliki broj njih se rukovodi i iskustvima drugih. Zbog toga treba obezbediti i dobre recenzije na različitim sajtovima. Zadovoljni turisti su najbolja reklama. Jedan od načina da se turistima obezbedi dodatna vrednost i unaprede njihova iskustva prilikom obilaska kulturno-istorijskog nasleđa, jeste upotreba IKT. Najpre, potrebno je obezbediti im besplatne mobilne turističke vodiče. Što je ova aplikacija kvalitetnija, to će oni njome biti zadovoljniji. Kakve su poželjne osobine ovih mobilnih aplikacija i kako koristiti proširenu stvarnost tj. AR, detaljno je diskutovano u ovom radu.

I ustanove kulture, poput galerija i muzeja, treba da ulažu u razvoj mobilnih aplikacija koje će personalizovati obilazak izložbi i učiniti ih zanimljivijim, tako što će posetiocima ponuditi zanimljiv prikaz informacija o izloženim delima. Svi veći muzeji i galerije u svetu poseduju jednu ovakvu mobilnu aplikaciju. A neki idu korak dalje, pa koriste i virtuelnu stvarnost, kako bi prikazali i dela koja nisu trenutno izložena, ili pak dočarali odakle ona potiču. Na osnovu svega izloženog, može se zaključiti da je nemoguće razvijati kulturni turizam bez upotrebe IKT. U budućnosti se samo može očekivati njihovo još intenzivnije korišćenje, jer će se ove tehnologije sve više razvijati i unapređivati.

\section{LITERATURA}

Axon Marketing \& Communications (March 19th, 2018) Meet The Five Influencer Marketing Trends in the Tourism Sector for 2018, https://www.axonlatam.com/en/update-with-our-contents/meet-the-five-influencermarketing-trends-in-the-tourism-sector-for-2018/, preuzeto 4. jula 2018.

Baechle, M., Daurer, S., Judt, A., \& Mettler, T. (2018). Chatbots as a User Interface for Assistive Technology in the Workplace, https://www.researchgate.net/profile/Stephan_Daurer/publication/325972403 Chatbots_as_a_User_Interface_for_Assistive_Technology_in_the_Workplace/links/5b30e5f90f7e $9 \mathrm{~b} 0$ df5c77261/Chatbots-as-a-User-Interface-for-Assistive-Technology-in-the-Workplace.pdf, preuzeto 15. septembra 2018.

Florian, D., Matera, M., Zaccaria, V., \& Dell'Orto, A. (2017) Toward Truly Personal Chatbots: On the Development of Custom Conversational Assistants, www.floriandaniel.it/papers/DanielSE4COG2018.pdf, preuzeto 15. septembra 2018.

Fritz, F., Susperregui, A., \& Linaza, M.T. (2005). Enhancing Cultural Tourism experiences with Augmented Reality Technologies. The 6th International Symposium on Virtual Reality, Archaeology and Cultural Heritage VAST, November 2005. DOI:10.1.1.622.4265\&rep=rep1\&type=pdf

Goss, J. (2016) Cultural Tourism: A Huge Opportunity and A Growing Trend, https://culturaltourism.thegossagency.com/cultural-tourism-whitepaper/, preuzeto 24. septembra 2018.

Hadžić, O. (2005) Kulturni turizam. Novi Sad: Prirodno-matematički fakultet. 
Hausmann, A., Weuster, L., \& Nouri-Fritsche, N. (2015). Making Heritage Accessible: Usage and Benefits of Web-based Applications in Cultural Tourism. International Journal of Cultural and Digital Tourism, 2(1), 19-30, http://iacudit.org/journal/volumes/v2n1/v2n1_19-30.pdf, preuzeto 27. juna 2018.

Hundertmark, S. (May 2018). Chatbot Usage - Actual Facts and Figures, https://www.linkedin.com/pulse/chatbot-usages-actual-facts-figures-sophie-hundertmark, preuzeto 15. septembra 2018.

Joksić, N. (2018). Chatbotovi kao budućnost online poslovanja, http://optimizacijasajta-internetmarketing.com/ chatbotovi-kao-buducnost-online-poslovanja/, preuzeto 15. septembra 2018.

Kečkeš, A.L., Tomičić, I. (2017). Augmented Reality in Tourism - Research and Applications Overview. Interdisciplinary Description of Complex Systems, 15(2), 157-167, DOI:10.7906/indecs.15.2.5

Kemp, S. (January 2018). Digital in 2018: World's Internet Users Pass the 4 Billion Mark, https://wearesocial. com/blog/2018/01/global-digital-report-2018, preuzeto 5. jula 2018.

Knežević, M., Borovčanin, D., Džamić, V., \& Radojević, T. (2017). Značaj društvenih mreža u promociji srpskih manastira, SITCON 2017: Verski turizam i savremeno turističko tržište, zbornik radova, 140-146. DOI: 10.15308/Sitcon-2017-140-147.

Lončarić, D., Bašan, L., \& Gligora Marković, M. (2015). Information search behaviour - Is there a gap between tourist needs and DMO website performance, Marketing insights from a changing environment (pp.3-23), London: Pearson.

Minazzi, R. (2015). Social Media Marketing in Tourism and Hospitality. Switzerland: Springer International Publishing.

Mondo (maj 2017) Chat botovi - sledeća veliki stvar, http://mondo.rs/a1011035/Mob-IT/Vesti/Chat-botovisledeca-veliki-stvar.html, preuzeto 15. septembra 2018.

Pivac, T. (2016). Kulturni turizam, www.dgt.uns.ac.rs/download/kultreligindturizam240516.pdf, preuzeto 24. juna 2018.

Qian, Y. F., Hu, J., \& Zhang, M. (2015). Study on the Online Travel Information Search: A Perspective of Social Media, Advances in Applied Sociology, 5, 219-233, https://file.scirp.org/pdf/AASoci_2015082615413282. pdf, preuzeto 24. juna 2018.

Rae, J., \& Edwards, L. (2016). Virtual reality at the British Museum: What is the value of virtual reality environments for learning by children and young people, schools, and families? MW2016: Museums and the Web 2016, https://mw2016.museumsandtheweb.com/paper/virtual-reality-at-the-british-museum-what-isthe-value-of-virtual-reality-environments-for-learning-by-children-and-young-people-schools-andfamilies/, preuzeto 4. jula 2018.

Richards, G. (2007). ATLAS Cultural Tourism Survey: Summary Report 2007, http://www.tram-research.com/ atlas/ATLAS Cultural Tourism Survey 2007.PDF, preuzeto 24. juna 2018.

Schroeder, A., \& Pennington-Gray, L. (2015). The Role of Social Media in International Tourist's Decision Making, Journal of Travel Research, 54(5), 584-595. DOI: 10.1177/0047287514528284

SEEcult.org (jun 2018). Narodni muzej i u virtuelnoj realnosti, http://www.seecult.org/vest/narodni-muzej-i-uvirtuelnoj-realnosti, preuzeto 28. juna 2018.

Silberberg, T. (1995). Cultural tourism and business opportunities for museums and heritage sites. Tourism Management 16(5), 361-365. DOI:10.1016/0261-5177(95)00039-q

Talwar, P. (2006). Travel And Tourism Management. New Delhi: Gyan Publishing House.

Vlada Republike Srbije (2016). Strategija razvoja turizma Republike Srbije za period od 2016. do 2025. godine, http://mtt.gov.rs/download/3/strategija.pdf, preuzeto 15. septembra 2018 


\title{
INFORMATION AND COMMUNICATIONS TECHNOLOGIES IN THE SERVICE OF CULTURAL TOURISM
}

\begin{abstract}
:
Cultural tourism market is becoming an ever more important tourist market segment as the number of cultural tourists is increasing year after year. However, competition between different cultural tourist destinations is also increasing. In the digital age we live in, tourists largely use Internet to search information while planning their trips. Therefore, a special attention should be paid to both presence on the Internet, as well as to social networks. Among other topics, this paper deals with how cultural tourists use information and communications technologies (ICT), and also what kind of web-sites should tourist organizations and cultural institutions have. In addition, the possibilities to use mobile applications in cultural tourism have also been investigated, especially the use of mobile tour guide systems and mobile applications for museums and galleries. One step beyond is the use of augmented reality, as well as virtual reality which is also presented in this paper. The use of modern technologies enables creating an added value for tourists and certainly contributes to their larger satisfaction, hence they are more likely to share their positive experiences on social networks and give positive ratings at certain web-sites, such as TripAdvisor. It is, however, possible to also use influencer marketing for the purpose of promoting a cultural tourism destination.
\end{abstract}

\section{Keywords:}

cultural tourism, social networks, mobile applications, augmented reality, virtual reality 